\title{
Clinico-Epidemiological Patterns of Cutaneous Leishmaniasis Patients Attending the Anuradhapura Teaching Hospital, Sri Lanka
}

\author{
Lahiru Sandaruwan Galgamuwa ${ }^{1,2}$, Buthsiri Sumanasena ${ }^{3}$, Lalani Yatawara ${ }^{4}$, \\ Susiji Wickramasinghe ${ }^{2}$, Devika Iddawela,* \\ ${ }^{1}$ Department of Basic Sciences, Faculty of Allied Health Sciences, General Sir John Kotelawala Defence University, Sri Lanka; ${ }^{2}$ Department of \\ Parasitology, Faculty of Medicine, University of Peradeniya, Peradeniya, Sri Lanka; ${ }^{3 T e a c h i n g ~ H o s p i t a l, ~ A n u r a d h a p u r a, ~ S r i ~ L a n k a ; ~}{ }^{4}$ Department of \\ Medical Laboratory Science, Faculty of Allied Health Sciences, University of Peradeniya, Peradeniya, Sri Lanka
}

\begin{abstract}
Cutaneous leishmaniasis (CL) caused by Leishmania donovani is an endemic vector-borne disease in Sri Lanka. Over 2,500 cases have been reported since 2000 and the number of $C L$ cases has dramatically increased annually. Total 57 clinically suspected CL patients attending the dermatology clinic in Anuradhapura Teaching Hospital were recruited from January to June 2015. Slit skin smears and skin biopsies were taken from each of the subjects. Clinical and epidemiological data were obtained using interviewer administered questionnaire. Forty-three (75.4\%) patients among 57 were confirmed positive for $L$. donovani. The majority of infected patients was males $(P=0.005)$, and the most affected age group was 21-40 years. Soldiers in security forces, farmers, and housewives were identified as high risk groups. The presence of scrub jungles around the residence or places of occupation $(P=0.003)$, the presence of sandflies $(P=0.021)$, and working outsides more than $6 \mathrm{hr}$ per day $(P=0.001)$ were significantly associated with $\mathrm{CL}$. The number of lesions ranged from 1-3, and the majority (76\%) of the patients had a single lesion. Upper and lower extremities were the prominent places of lesions, while the wet type of lesions were more prevalent in females $(P=0.022)$. A nodular-ulcerative type lesion was common in both sexes. The presence of sandflies, scrub jungles, and outdoor activities contributed to spread of Leishmania parasites in an endemic pattern. Implementation of vector control programs together with health education with regard to transmission and prevention of $\mathrm{CL}$ are necessary to control the spread of this infection.
\end{abstract}

Key words: Leishmania donovani, cutaneous leishmaniasis, clinico-epidemiological pattern, Sri Lanka

\section{INTRODUCTION}

Leishmaniasis is a vector-borne disease caused by a protozoan parasite of the genus Leishmania. The disease is transmitted by the bite of an infected female phlebotomine sandfly of the genera Phlebotomus and Lutzomia. Main clinical presentations of leishmaniasis include cutaneous, diffuse cutaneous, mucutaneous, and visceral. The main species responsible for visceral leishmaniasis (VL) is Leishmania donovani. Other species, including Leishmania tropica, Leishmania major, and Leishmania brasiliensis, cause cutaneous and muco-cutaneous leishmaniasis, respectively. The etiological agent responsible for cutane-

\footnotetext{
- Received 29 September 2016, revised 31 December 2016, accepted 8 January 2017.

*Corresponding author (devikaiddawela@yahoo.com)

(c) 2017, Korean Society for Parasitology and Tropical Medicine

This is an Open Access article distributed under the terms of the Creative Commons Attribution Non-Commercial License (http://creativecommons.org/licenses/by-nc/4.0) which permits unrestricted non-commercial use, distribution, and reproduction in any medium, provided the original work is properly cited.
}

ous leishmaniasis (CL) in Sri Lanka has been identified as $L$. donovani of the zymodeme MON-37 [1], which is closely related to the causative organism of $\mathrm{VL}$ in the Indian subcontinent. The number of leishmaniasis patients has increased in the last few decades mainly due to human migration from non-endemic to endemic areas, poverty, deforestation, urbanization, and adaptation of the Leishmania parasites to additional vectors and mammalian hosts [2-4]. Leishmaniasis is endemic in 88 countries [5]. About 350 million people are at risk of contracting Leishmania infection, and as many as 12 million people in the world are believed to be currently infected with 1.5-2 million new cases being reported [6]. The diversity in the clinical manifestations and epidemiological characteristics of the disease depend on the invasiveness, pathogenicity, and tropism of the infected Leishmania species and the immune responses of the host [7].

In Sri Lanka, the first case of locally acquired CL was reported in 1992 [8]. Since then, CL cases have been increased, and 
the prevalence is slowly rising to epidemic proportions. Over 2,000 cases have been reported in the last decade in North Central, North Eastern, and Southern Provinces [9]. Since 2008, CL has been recognized as a notifiable disease by the Ministry of Health, Sri Lanka. According to the epidemiological data, Anuradhapura is one of the highest endemic districts for CL in Sri Lanka. However, clinical data and epidemiological factors associated with CL are scarce in Anuradhapura district. Therefore, the aim of the present study was to describe the clinical and epidemiological aspects of CL patients attending Anuradhapura Teaching Hospital.

\section{MATERIALS AND METHODS}

\section{Data collection}

Anuradhapura is the largest district in Sri Lanka with an area of 7,179 km². The estimated population was 856,232 in 2015 and more than $90 \%$ live in rural areas involving agriculture related activities. The annual rainfall in this area is about 1,240 $\mathrm{mm}$ with the average temperature ranging between $20^{\circ} \mathrm{C}$ and $30^{\circ} \mathrm{C}$. Anuradhapura Teaching Hospital (ATH) is the only hospital with a leishmaniasis clinic in this district, and suspected CL cases are referred from peripheral hospitals to this clinic. Patients attending the dermatology clinic in ATH with lesions clinically suspected to have CL were included in this study from January to July 2015. Before collecting samples, written consent was obtained from all the patients who were willing to participate in the study. Individual records for each patient were made on an information sheet. Demographic data (age, sex, occupation, and area of residence) and clinical detail of the lesions (site, size, type of lesion, number of lesions, duration of the lesion, and inflammatory signs) were collected by an interviewer administered questionnaire. The past history of similar lesions in family members or neighbors and the presence of sandflies, rearing animals, and the presence of scrub jungles in the areas of their residence or place of occupation were also documented to determine the degree of exposure to the sandfly vector.

\section{Sample collection and parasite identification}

Samples were collected from each patient before starting treatment. A 3-4 $\mathrm{mm}$ nick at the edge of the lesion was made by a sterile scalpel, and the tissue fluid was smeared on a glass slide. When a patient has multiple lesions, several samples were obtained from each lesion. In addition, skin biopsy spec- imens were obtained from the active edge of the lesions by the dermatologists under sterile conditions. Biopsy samples were then stored in liquid nitrogen and transported to the Department of Parasitology, Faculty of Medicine for molecular studies. Smears on glass slides were air dried and fixed in methanol. The smears were stained with Giemsa and examined under oil immersion $(\times 100)$ for Leishmania amastigotes.

\section{DNA extraction and PCR}

DNA was extracted from each skin tissue biopsy sample separately according to the manufacturer's protocol using Pure Link $^{\mathrm{TM}}$ Genomic DNA Mini Kit (Invitrogen Life Technologies, Carlsbad, California, USA). PCR was performed using the PCR mixture containing $5 \mu \mathrm{l}$ of template DNA, $2.5 \mu \mathrm{l}$ of $5 \mathrm{x}$ reaction buffer, $2.0 \mu \mathrm{l}$ of $2.5 \mathrm{mM}$ dNTPs, $2.0 \mu \mathrm{l}$ of $25 \mathrm{mM} \mathrm{MgCl}_{2}, 5 \mathrm{U} / \mu \mathrm{l}$ Taq DNA polymerase, and $1.5 \mu \mathrm{l}$ of $10 \mu \mathrm{M}$ of each primer (5'-CGGCTTCGCACCATGCGGTG-3'; 5'-ACATCCCTGCCCACATACGC-3') in a total volume of $25 \mu \mathrm{l}$. Primers used in this study were amplified to $260 \mathrm{bp}$ fragment specific to old world Leishmania spp. [10]. PCR amplifications were carried out in a thermocycler Thermolyne Amplitronyx ${ }^{\mathrm{TM}}$. The PCR conditions were $2 \mathrm{~min}$ at $95^{\circ} \mathrm{C}$ followed by 40 cycles of $30 \mathrm{sec}$ at $94^{\circ} \mathrm{C}$, 30 sec at $56^{\circ} \mathrm{C}$, and $20 \mathrm{sec}$ at $72^{\circ} \mathrm{C}$. PCR products were electrophoresed on $1.5 \%$ agarose gels and visualized after ethidium bromide staining. CL was confirmed by positive findings from 1 of these 2 methods (microscopy and/or PCR).

\section{Statistical analysis}

The data were entered into a Microsoft Excel sheet, and were transferred into SPSS 20.0 for statistical analysis. Descriptive statistics and frequency distributions were performed to describe independent variables. Fisher's exact test was used to determine the factors associated between exposure and clinical presentations with CL. P-values of less than 0.05 were considered as statistically significant.

\section{Ethical clearance}

Ethical approval was obtained from the Ethical Review Committee, Faculty of Medicine, University of Peradeniya, Sri Lanka. Permission to conduct the study was gained from the administration of the Anuradhapura Teaching Hospital. Written informed consent was obtained from each adult participant and from either of the parents or the legal guardian of children younger than 18 years of age. 


\section{RESULTS}

\section{Disease prevalence and socio-demographic characteristics}

Total 57 CL suspected patients attending to Leishmania dermatology clinic in Anuradhapura Teaching Hospital were recruited for this study before starting their treatments. Out of the 57 samples, 38 (66.7\%) were positive for Leishmania amastigotes by light microscopy, and 43 (75.4\%) were clinically diagnosed and tested positive for $L$. donovani by PCR (Fig. 1). Five microscopy negative samples were identified as CL positive by PCR. Of CL positive patients, the majority (77\%) were males. Ages of the participants ranged from 15 to 67 years (mean age, $37.8 \pm 12.6$ years), and the majority of patients were aged between 21 to 40 years (Fig. 2). CL positivity of males was significantly higher than that of females $(P=0.005)$.

CL infection was common among farmers and security service personnel (Table 1). These patients were from 5 administrative districts located in North and North Central Provinces

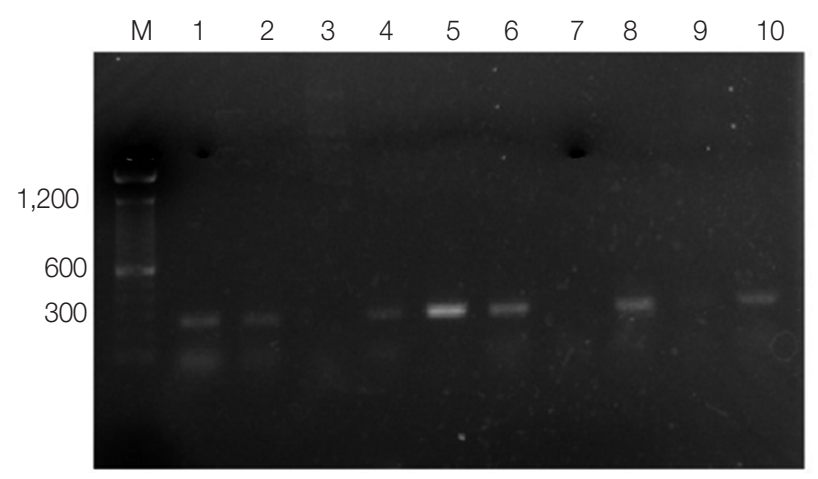

Fig. 1. Ethidium bromide stained agarose gel of PCR products of Lesihmania species (CL) from patients. M, molecular marker (100 bp); lanes 1, 2, 4, 5, 6, and 8, positive samples; lanes 3 and 7, negative samples; lane 9, negative control; lane 10, positive control. in Sri Lanka. Most of the patients $(32 / 43 ; 74 \%)$ were from rural areas of the Anuradhapura district. The rest was from Mullaithivu (8/43), Mannar (1/43), Vavunia (1/43), and Kilinochchi $(1 / 43)$ districts. The majority $(86 \%)$ of the patients had scrub jungles and sandflies around their residence or occupational places. A large proportion of CL patients (23/43) had

Table 1.Occupational distribution of $C L$ patients

\begin{tabular}{lrr}
\hline Occupation & No. of CL patients & $\%$ \\
\hline Army soldiers & 14 & 32.6 \\
Farm workers & 10 & 23.3 \\
Housewives & 9 & 20.9 \\
Field officers & 2 & 4.7 \\
Teachers & 2 & 4.7 \\
Businessmen & 2 & 4.7 \\
Students & 2 & 4.7 \\
Sales executive & 1 & 2.3 \\
Carpenter & 1 & 2.3 \\
Total & 43 & 100.0 \\
\hline
\end{tabular}

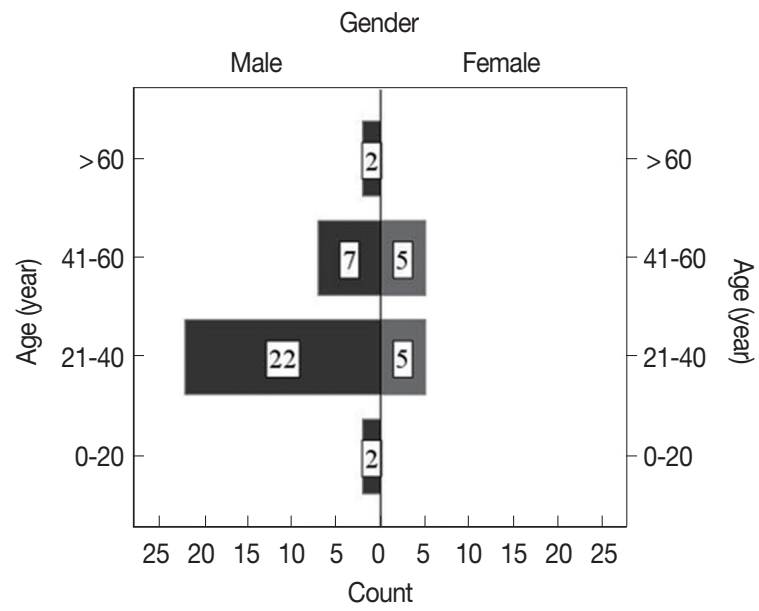

Fig. 2. Age and sex distribution of CL patients.

Table 2. Frequency distribution of details of exposure

\begin{tabular}{|c|c|c|c|c|}
\hline Variables & Categories & CL positives $(n=43)$ & CL negatives $(n=14)$ & $P$-value \\
\hline Presence of rear animals & $\begin{array}{l}\text { Yes } \\
\text { No }\end{array}$ & $\begin{array}{l}18 \\
25\end{array}$ & $\begin{array}{l}6 \\
8\end{array}$ & 1.000 \\
\hline Presence of sandflies & $\begin{array}{l}\text { Yes } \\
\text { No }\end{array}$ & $\begin{array}{l}32 \\
11\end{array}$ & $\begin{array}{l}5 \\
9\end{array}$ & 0.021 \\
\hline Presence of CL lesions in family members or neighbors & $\begin{array}{l}\text { Yes } \\
\text { No }\end{array}$ & $\begin{array}{l}23 \\
20\end{array}$ & $\begin{array}{r}4 \\
10\end{array}$ & 0.132 \\
\hline Presence of scrub jungles around the residence/occupation place & $\begin{array}{l}\text { Yes } \\
\text { No }\end{array}$ & $\begin{array}{r}37 \\
6\end{array}$ & $\begin{array}{l}6 \\
8\end{array}$ & 0.003 \\
\hline Outdoor activities more than $6 \mathrm{hr}$ per day & $\begin{array}{l}\text { Yes } \\
\text { No }\end{array}$ & $\begin{array}{r}36 \\
7\end{array}$ & $\begin{array}{l}5 \\
9\end{array}$ & 0.001 \\
\hline Dwelling area & $\begin{array}{l}\text { Rural } \\
\text { Urban }\end{array}$ & $\begin{array}{r}40 \\
3\end{array}$ & $\begin{array}{r}11 \\
3\end{array}$ & 0.151 \\
\hline
\end{tabular}


Table 3. Clinical presentations of CL patients

\begin{tabular}{|c|c|c|c|c|c|}
\hline Variables & Categories & Male patients & Female patients & Total (\%) & $P$-value \\
\hline \multirow[t]{2}{*}{ Age (year) } & $0-40$ & 23 & 6 & $29(67.4)$ & 0.704 \\
\hline & $>40$ & 10 & 4 & $13(32.6)$ & \\
\hline \multirow[t]{2}{*}{ Number of lesions } & 1 & 26 & 7 & $33(76.7)$ & 0.674 \\
\hline & 2 & 7 & 3 & $10(23.3)$ & \\
\hline \multirow[t]{5}{*}{ Sites of lesions } & Upper limbs & 17 & 5 & $22(41.5)$ & 0.553 \\
\hline & lower limbs & 12 & 5 & $17(32.1)$ & \\
\hline & Face & 4 & 3 & 7 (13.2) & \\
\hline & Neck & 4 & 0 & $4(7.5)$ & \\
\hline & Back & 3 & 0 & $3(5.7)$ & \\
\hline \multirow[t]{3}{*}{ Duration of lesions (month) } & $<6$ & 23 & 9 & $32(60.4)$ & 0.886 \\
\hline & $6-12$ & 13 & 3 & $16(30.2)$ & \\
\hline & $>12$ & 4 & 1 & $5(9.4)$ & \\
\hline \multirow[t]{3}{*}{ Size of lesions $\left(\mathrm{mm}^{2}\right)$} & $50-100$ & 22 & 11 & $33(62.3)$ & 0.157 \\
\hline & $101-200$ & 14 & 2 & $16(30.2)$ & \\
\hline & $>200$ & 4 & 0 & $4(7.5)$ & \\
\hline \multirow[t]{3}{*}{ Types of lesions } & Papulo-nodular & 15 & 4 & $19(35.8)$ & 0.379 \\
\hline & Nodular-ulcerative & 16 & 8 & 24 (45.3) & \\
\hline & Ulcers & 9 & 1 & $10(18.9)$ & \\
\hline \multirow[t]{2}{*}{ Inflammatory signs } & Yes & 30 & 10 & $40(75.5)$ & 1.000 \\
\hline & No & 10 & 3 & $13(24.5)$ & \\
\hline \multirow[t]{2}{*}{ Other features } & Dry CL & 30 & 5 & $35(66.0)$ & 0.022 \\
\hline & Wet CL & 10 & 8 & $18(34.0)$ & \\
\hline
\end{tabular}

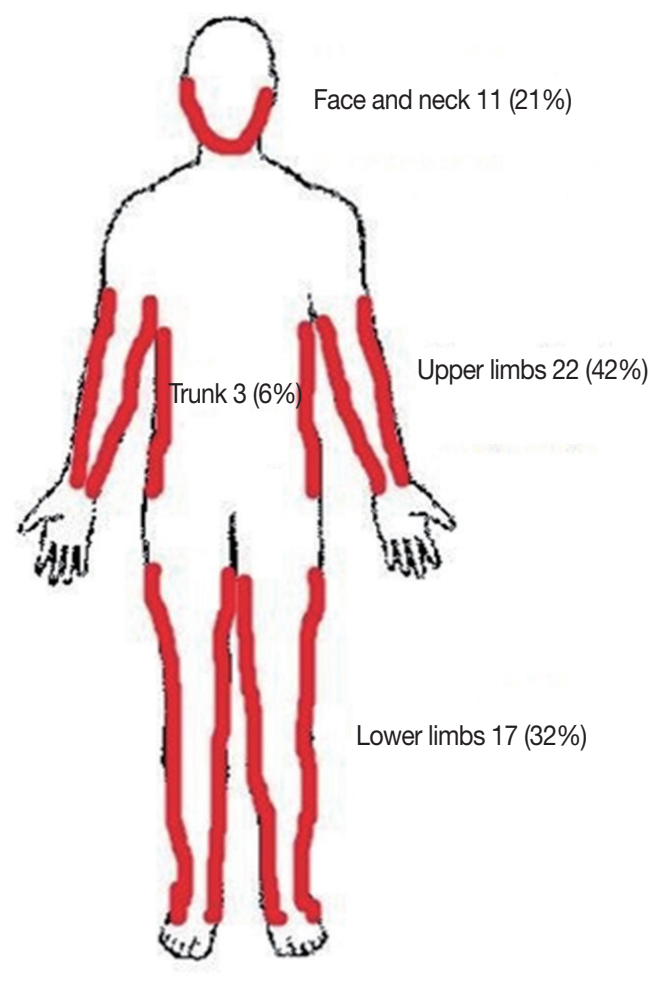

Fig. 3. Distribution of CL lesions on infected patients.

infected family members or neighbors. None of the patients had overseas travel history. Therefore, it was assumed that all of them were infected locally. Existence of scrub jungles around residence or occupational places $(P=0.003)$, presence of sandflies $(P=0.021)$ and working outsides more than $6 \mathrm{hr}$ per day $(P=0.001)$ were significantly associated with CL. However, CL lesions in family members or neighbors, rearing animals, and living in rural or urban areas were not significantly associated with CL $(P>0.05)$ (Table 2).

\section{Clinical manifestations of CL patients}

The majority (77\%) had a single lesion while the rest had multiple lesions. The duration of cutaneous lesions ranged from 6 weeks to 4 years (mean duration, $6.0 \pm 4.3$ months). Lesions were frequently seen on the upper limbs (42\%) followed by lower limbs (32\%), face (13\%), and other parts of the body (Table 3), (Fig 3). No lesions were found on the soles, head, and genital areas. Diffuse leishmaniasis was not found in the current study. The size of the lesions ranged from 4 to $35 \mathrm{~mm}$ in diameter, and the majority of lesions had a surface area between 50-100 $\mathrm{mm}^{2}$. The commonest type of lesion was nodular-ulcerative in both sexes. More than a half (66\%) had dry lesions. The presence of wet lesions was significantly more common in female patients compared to males $(P=0.022)$. 


\section{DISCUSSION}

This study showed that, among clinically diagnosed CL cases attending the Anuradhapura Teaching Hospital between January to July 2015, the majority had Leishmania amastigotes in their lesions indicating considerably high level of transmission in the North Central Province of Sri Lanka. According to our findings, adults were at a higher risk of contracting the infection due to their activities and/or occupation than children. This is in agreement with a previous report published in Sri Lanka [11]. CL was common among young adults aged between 21 to 40 years. Similar findings were reported in previous studies conducted in the North Central, North Western, and Central Provinces in Sri Lanka [12,13] and in India [14]. People in this age group are at a higher risk of exposure due to their high activity levels, occupation, and education. The highest prevalence in the Southern part of Sri Lanka was reported in patients aged 10-19 years [15].

Most of the patients in this study group had single lesions. Similar lesion pattern was reported in studies conducted in India and Tunisia. Lesions were more common in the upper limbs in our study. Siriwardena et al. [16] reported similar findings. The face and lower limbs had lesions similar to findings of other studies conducted in Sri Lanka [12] and in other countries $[14,17]$. These findings suggest that exposed parts of the body are more prone to sandfly bite. Lesions were not detected in the neck and waist area in female patients due to the covering of these areas by garments. In the present study, CL infection was higher among males than females. This is consistent with previous studies conducted in Sri Lanka $[16,18,19]$. Similar findings were reported in Libya, Pakistan, and Iran [2022]. This observation could be because men are more likely to work in open environments, such as agricultural farms and fields, where they refrain from covering the upper half of their bodies and their limbs, thus increasing the risk of exposure to sandfly bites. Our results confirmed that people whose occupations are closely related to scrub jungles and forests are more prone to sandfly bites. The results are supported by previous studies conducted in the North and North Central Provinces, in Sri Lanka [23]. However, in India and Surinam, leishmaniasis was common among students and housewives $[24,25]$. Animal husbandry (rearing cows) is one of the main occupations in this area. In the present study, $42 \%$ of patients confirmed that rearing animals are abundant around their households. According to several studies, some animals (dogs and goats) have been identified as reservoir hosts for leishmaniasis $[26,27]$. However, the definite reservoir host has not been identified in Sri Lanka as of yet, although Leishmania amastigotes and antigens have been detected in dogs $[22,28]$. Almost all (93\%) of the cases were from rural areas of the North and North Central Provinces. This could be due to the abundance of sandfly breeding sites, reservoir hosts, and natural habitats in the rural areas.

In the present study, the average time taken for the patient to present to dermatological clinic after acquiring the lesion was 6 months. The time taken to seek medical advice compares unfavorably to the mean average time reported by Aara et al. [29].

Dry type CL lesions were common in this study group, in agreement with previous studies conducted in Sri Lanka [12], India [30], Libya [31], and in Syria [32]. However, females had more wet lesions than males. In this study, nodulo-ulcerative lesions were the commonest type of lesion observed. This is in agreement with previous reports published in Sri Lanka [12]. The clinical appearance of cutaneous lesions varies depending of the immunity of the patient [33] and the species or strain of the causative agent [34]. The study reported a considerably large proportion of leishmaniasis patients among clinically suspected patients. However, we could not determine the prevalence of this infection in this area since we did not carry out active case detection. Therefore, further studies are needed to determine the prevalence, risk factors, and degree of exposure.

However, outdoor occupations and activities increase the risk of exposure to CL infections. The presence of sandflies and rearing animals contributes to the spread of Leishmania parasites in an endemic pattern. Therefore, implementation of vector control programs together with health education focused on the transmission and preventive methods of $\mathrm{CL}$ are necessary to limit the spread of this infection.

\section{ACKNOWLEDGMENTS}

The authors are thankful to the dermatologists in Anuradhapura Teaching hospital for their massive supports to get biopsy and smear samples. This study was funded by University of Peradeniya, Sri Lanka under grant no. RG/AF/2013/34.

\section{CONFLICT OF INTEREST}

We have no conflict of interest related to this work. 


\section{REFERENCES}

1. Karunaweera ND, Pratlong F, Siriwardane HV, Ihalamulla RL, Dedet JP. Sri Lankan cutaneous leishmaniasis is caused by Leishmania donovani zymodeme MON-37. Trans R Soc Trop Med Hyg 2003; 97: 308-381.

2. Reithinger R, Dujardin JC, Louzir H, Pirmez C, Alexander B, Brooker S. Cutaneous leishmaniasis. Lancet Infect Dis 2007; 7: 581-596.

3. Goto H, Lindoso JA. Current diagnosis and treatment of cutaneous and mucocutaneous leishmaniasis. Expert Rev Anti Infect Ther 2010; 8: 419-433.

4. Ferro C, Marín D, Góngora R, Carrasquilla MC, Trujillo JE, Rueda NK, Marín J, Valderrama-Ardila C, Alexander N, Pérez M, Munstermann LE, Ocampo CB. Phlebotomine vector ecology in the domestic transmission of American cutaneous leishmaniasis in Chaparral, Colombia. Am J Trop Med Hyg 2011; 85: 847-856.

5. WHO. Leishmaniasis, 2012. (available: http://www.who.int/ leishmaniasis/burden/en/) [29 September 2012].

6. WHO. Control of the leishmaniases: Report of a meeting of the WHO Expert Committee on the Control of Leishmaniases, 2010. (available: http://apps.who.int/iris/bitstream/10665/44412/1/ WHO_TRS_949_eng.pdf) [2 January 2011].

7. Bari AU. Clinical spectrum of cutaneous leishmaniasis: an overview from Pakistan. Dermatol Online J 2012; 18: 4.

8. Athukorale DN, Seneviratne JK, Ihalamulla RL, Premaratne UN. Locally acquired leishmaniasis in Sri Lanka. J Trop Med Hyg 1992; 95: 432-433.

9. Siriwardana HV, Thalagala N, Karunaweera ND. Clinical and epidemiological studies on the cutaneous leishmaniasis caused by Leishmania donovani in Sri Lanka. Ann Trop Med Parasitol 2010; 104: 213-223.

10. Piarroux R, Fontes M, Perasso R, Gambarelli F, Joblet C, Dumon H, Quilici M. Phylogenetic relationship between old world Leishmania strains revealed by analysis of a repetitive DNA sequence. Mol Biochem Parasitol 1995; 73: 249-252.

11. Ranasinghe S, Wickremasinghe R, Munasinghe A, Hulangamuwa S, Sivanantharajah S, Seneviratne K, Bandara S, Athauda I, Navaratne C, Silva O, Wackwella H, Matlashewski G, Wickremasinghe R. Cross-sectional study to assess risk factors for leishmaniasis in an endemic region in Sri Lanka. Am J Trop Med Hyg 2013; 89: 742-749.

12. Nawaratna SS, Weilgama DJ, Wijekoon CJ, Dissanayake M, Rajapaksha K. Cutaneous leishmaniasis, Sri Lanka. Emerg Infect Dis 2007; 13: 1068-1070.

13. Sandanayaka R, Kahawita I, Gamage A, Siribaddana S, Agampodi S. Emergence of cutaneous leishmaniasis in Polonnaruwa, Sri Lanka 2008-2011. Trop Med Int Health 2014; 19: 140-145.

14. Sharma NL, Mahajan VK, Kanga A, Sood A, Katoch VM, Mauricio I, Singh CD, Parwan UC, Sharma VK, Sharma RC. Localized cutaneous leishmaniasis due to Leishmania donovani and Leishmania tropica: preliminary findings of the study of 161 new cases from a new endemic focus in Himachal Pradesh, India. Am J Trop Med
Hyg 2005; 72: 819-824.

15. Rajapaksa US, Ihalamulla RL, Udagedera C, Karunaweera ND. Cutaneous leishmaniasis in Southern Sri Lanka. Trans R Soc Trop Med Hyg 2007; 101: 799-803.

16. Siriwardana HV, Udagedara CU, Karunaweera ND. Clinical features, risk factors and efficiency of cryotherapy in cutaneous leishmaniasis in Sri Lanka. Ceylon Med J 2003; 48: 10-12.

17. Ranawaka RR, Abeygunasekara PH, Weerakoon HS. Correlation of clinical, parasitological and histopathological diagnosis of cutaneous leishmaniasis in an endemic region in Sri Lanka. Ceylon Med J 2012; 57: 149-152

18. Nawaratna SS, Weilgama DJ, Rajapaksha K. Cutaneous leishmaniasis in Sri Lanka: a study of possible animal reservoirs. Int J Infect Dis 2009; 13: 513-517.

19. Abdellatif MZ, El-Mabrouk K, Ewis AA. An epidemiological study of cutaneous leishmaniasis in Al-jabal Al-gharbi, Libya. Korean J Parasitol 2013; 51: 75-84.

20. Birjees MK. Epidemiology of cutaneous leishmaniasis in Larkana district of Sindh province with particular reference to phlebotomine sandflies. Public Health Division, National Institute of Health (Islamabad) 2001; 67: 1-67.

21. Haddad MHF, Kassiri H, Kasiri N, Panahandeh A, Lotfi M. Prevalence and epidemiologic profile of acute cutaneous leishmaniasis in an endemic focus, Southwestern Iran. J Acute Dis 2015; 4: 292-297

22. Ranawaka RR, Weerakoon HS, Opathella N Subasinha C. Leishmaniasis in the North central province, Sri Lanka-epidemiology and therapeutic response. Sri Lanka J Dermatol 2010; 14: 4-8.

23. Aara N, Khandelwal K, Bumb RA, Mehta RD, Ghiya BC, Jakhar R, Dodd C, Salotra P, Satoskar AR. Clinco-epidemiologic study of cutaneous leishmaniasis in Bikaner, Rajasthan, India. Am J Trop Med Hyg 2013; 89: 111-115.

24. van der Meide WF, Jensema AJ, Akrum RA, Sabajo LO, Lai A Fat RF, Lambregts L, Schallig HD, van der Paardt M, Faber WR. Epidemiology of cutaneous leishmaniasis in Suriname: a study performed in 2006. Am J Trop Med Hyg 2008; 79: 192-197.

25. Rohousova I, Talmi-Frank D, Kostalova T, Polanska N, Lestinova T, Kassahun A, Yasur-Landau D, Maia C, King R, Votypka J, Jaffe CL, Warburg A, Hailu A, Volf P, Baneth G. Exposure to Leishmania spp. and sand flies in domestic animals in north western Ethiopia. Parasit Vectors 2015; 8: 360.

26. Dantas-Torres F. The role of dogs as reservoirs of Leishmania parasites, with emphasis on Leishmania (Leishmania) infantum and Leishmania (Viannia) braziliensis. Vet Parasitol 2007; 149: 139-146.

27. Rosypal AC, Tripp S, Kinlaw C, Hailemariam S, Tidwell RR, Lindsay DS, Rajapakse RP, Sreekumar C, Dubey JP. Surveillance for antibodies to Leishmania spp. in dogs from Sri Lanka. J Parasitol 2010; 96: 230-231.

28. Aara N, Khandelwal K, Bumb RA, Mehta RD, Ghiya BC, Jakhar R, Dodd C, Salotra P, Satoskar AR. Clinco-epidemiologic study of cutaneous leishmaniasis in Bikaner, Rajasthan, India. Am J Trop Med Hyg 2013; 89: 111-115.

29. Zaraa I, Ishak F, Kort R, El Euch D, Mokni M, Chaker E, Ben Os- 
man A. Childhood and adult cutaneous leishmaniasis in Tunisia. Int J Dermatol 2010; 49: 790-793.

30. Agrawal S, Khandelwal K, Bumb RA, Oghumu S, Salotra P, Satoskar AR. Pediatric cutaneous leishmaniasis in an endemic region in India. Am J Trop Med Hyg 2014; 91: 901-904.

31. Belal US, Abdel-Hafeez EH, Naoi K, Norose K. Cutaneous leishmaniasis in the Nalut District, Libyan Arab Jamahiriya: a clinicoepidemiologic study and Leishmania species identification. J Parasitol 2012; 98: 1251-1256.

32. Alam E, Abbas O, Moukarbel R, Khalifeh I. Cutaneous leishmaniasis: an overlooked etiology of midfacial destructive le- sions. PLoS Negl Trop Dis 2016; 10: e0004426.

33. Guessous-Idrissi N, Chiheb S, Hamdani A, Riyad M, Bichichi M, Hamdani S, Krimech A. Cutaneous leishmaniasis: an emerging epidemic focus of Leishmania tropica in north Morocco. Trans R Soc Trop Med Hyg 1997; 91: 660-663.

34. Khan NH, Bari AU, Hashim R, Khan I, Muneer A, Shah A, Wahid S, Yardley V, O'Neil B, Sutherland CJ. Cutaneous leishmaniasis in Khyber Pakhtunkhwa province of Pakistan: clinical diversity and species-level diagnosis. Am J Trop Med Hyg. 2016; 95: 1106-1114. 